\title{
DIMENSIONANDO O ESPAÇO DA FAMÍLIA, \\ NO ÂMBITO DO PÚBLICO E DO PRIVADO
}

Coleta Rinaldi A Ithoff ${ }^{1}$

RESUM O: Reflexão sobre o espaço da família no âmbito do público e do privado, dentro de um ponto de vista teórico, no qual enfoca os aspectos relacionados a origem da família e a dimensão de seu lugar no contexto histórico e no presente momento.

DESCRITORES: Família; Comportamento social.

\section{REDRAWING FAMILY BOUNDARIES IN THE PUBLIC AND PRIVATE REALM}

ABSTRACT: A reflexion on the role of the family in the public and private real $m$, according a theoretical perspective in witch the aspects related to the origin of the family as an instituition and is dimention in the historic context and nowadays are focused.

KEYWORDS: Family; Social behavior.

\footnotetext{
${ }^{1}$ Professora A djunta II do Departamento de Enfermagem da Universidade Federal de Santa Catarina (UFSC). D outoranda em Filosofia da Enferma-
} gem-UFSC. 


\section{INTRODUÇÃO}

Situar a família em espaços distintos o público e 0 privado, nos faz pensar na sua origem como instituição social, na complexidade de sua estrutura modificada ao longo do tempo. Esse processo de mudança parece Ter influenciado a maneira de como ela se organizou para cuidar de seus membros. Dentro de cada sistema de organização da sociedade os indivíduos sofreram e continuam a experimentar transformações significativas, cujas ações têm influenciado a sua forma de viver. Como parte do corpo social, a família tem suas crenças e seus valores, cujas características fazem parte de um núcleo de determinado momento histórico e de determinada local ização geográfica. A importância de destacar os espaços no âmbito do público e do privado está em situar a família como integrante do contexto social, cuja estrutura é determinada pelas relações sociais no exercício e na defesa dos interesses comuns e na compreensão de suas práticas de cuidado do ser humano, especialmente da criança, como ser em formação.

\section{UM A PERSPECTIVATEÓRICA}

$\mathrm{Na}$ literatura, o termo família encontra-se definido de acordo com a estrutura e as funções de cada sociedade, em determinados períodos históricos. Segundo Engels (1995,p.61) "em sua origem a palavra família não significa o ideal - de sentimentalismo edissensões domésticas - do filisteu de nossa época; a princípio, entre os romanos, (...) famulus quer dizer escravo doméstico e família é o conjunto de escravos pertencentes ao mesmo homem." 0 autor declara ainda que "a expressão foi inventada pelos romanos para designar um novo organismo social, cujo chefe mantinha sob seu poder a mulher, os fil hos e certo número de escravos, com pátrio poder romano e o direito de vida e morte sobre eles. "A inda hoje, para os italianos, o termo família refere-se a toda rede de parentesco ampliada, e que tende a viver em estreita proximidade. U ma definição mais ampla, que vai além dos laços de sangue, até amigos de muito tempo é apresentada pela população negra. Já na sociedade americana, o que prevalece éa família nuclear, enquanto os chineses incluem todos os seus ancestrais e descendentes (Carter e M c Goldrich, 1995).V árias outras designações são apresentadas pelos estudiosos da área, demarcando as características de cada grupo social em face do meio físico, político, social e cultural observado. Então, para os diversos grupos, há uma maneira de considerar o que constitui a família. Não se pode admitir a afirmação de que há uma única forma de estrutura familiar, mas uma diversidade, com modos de ser particulares, encontrada na maioria da população. Desde os primórdios, essas estruturas sofrem modificações deforma a atender as necessidades de cada grupo.

A partir da identificação das famílias entre as tribos primitivas, denominadas consaguíneas, punuluana esidiásmica, as quais eram formadas no regime de matrimônio por grupos, segundo relato apresentado por Engels (1995), até a predominância da família nuclear na sociedadecontemporânea, percebe-sea presença de diferentes estruturas familiares. Estas se organizam segundo um model o padronizado de convivência ou de acordo com o modo como os indivíduos percebem a realidade e se mantêm para sobreviver.

A história das famílias revela a evolução progressiva da forma de relacionamento entre os indivíduos. Nos tempos pré-históricos, o vínculo conjugal original mente relaizado entre irmãos e irmãs por gerações sucessivas, passou por uma fase detransição progressiva, primeiro com a exclusão dos parentes próximos, depois dos parentes distantes e por fim das pessoas vinculadas apenas por aliança. Do matrimônio por grupos, 0 vínculo ficou reduzido a um homem ea uma mul her, compondo a família individual, que passou a constituir a unidade econômica da sociedade. Surgiu a divisão de trabalho na família, cabendo ao homem procurar a alimentação e os instrumentos de trabal ho necessários, mesmo os escravos. As riquezas, à medida que iam aumentando, deram ao homem uma posição mais importante que à mulher, na família. 0 homem apoderou-se da direção da casa, e a mulher vu-se convertida em servidora e instrumento de reprodução, constituindo-se na família patriarcal (ENGELS, 1995).

Da família patriarcal considerada a célula social e a base dos Estados, derivou a família nuclear (ARIĖS,1981). Esta forma de organização familiar, composta de mãe, pai e filho, constitui o modelo normativo, dominante na nossa sociedade. A idéia de que a família nuclear passou a ser considerada como padrão faz com que as outras formas encontradas na sociedade tendem a ser definidas em relação às características apresentadas por este tipo de família. D esta maneira, com a existência do modelo normativo, as outra estruturas familiares são definidas como desorganizads, desestruturadas ou incompletas e consideradas muitas vezes, como responsáeis pelo fracasso escolar, pela violência, pelo abandono das crianças e pela marginalização dos jovens (M ELL 0,1995; SZY M A N SK I, 1995). D evido à diversidade de formas familiares, torna-se difícil encontrar um conceito universal de família.

Os seres humanos, ao buscarem uma forma de convivência e de aproximação por interesses afetivos, sociais, econômicos ou legais, constroem um modo de viver de acordo com a sua realidade. Segundo A rendt (1989, p.31) "nenhuma vida humana, nem mesmo a vida do eremita em meio ànatureza selvagem, é possível sem um mundo que, direta ou indiretamente, testemunhe a presença de outros seres humanos". Para a vida em comum, o homem estabeleceu uma maneira de viver e atender à suas necessidades mediante uma forma de organização.

Se afamília éconsiderada como forma de organização social, como está ela situada neste mundo? U ma das maneiras debuscar um entendimento estána concepção demundo social, no qual se distingue uma esfera da vida privada e uma esfera da vida publica. Á ries e Duby (1994, p.19-20), ao buscarem o significado dos conceitos a partir das palavras, identificaram que 0 adjetivo privado "conduz à idéia de familiaridade e

Cogitare Enferm., Curitiba, v. 1 n. 2, p. 35-38 - jul./dez. 1996 
agrega-se a um conjunto constituído em torno da idéia de família, de casa, de interior; o verbo priovar significa domar, domesticar". Quanto à palavra público, diz respeito "ao queé comum, para uso de todos". Esta distinção surgiu com a antiga cidade-estado designada pelos gregos, na qual apontavam a existência destas duas esferas, como entidades diferentes e separadas. Nessa épooca, o termo público estava relacionado a dois fenômenos. 0 primeiro significava que tudo que vem a público pode ser visto e ouvido por todos, e tem a maior divulgação possível. 0 segundo considerava o próprio mundo, à medida que é comum a todos nós, e diferente do lugar que nos cabe dentro dele (A RENDT, 1989, p.62). Q uanto ao termo privado, originário de privação, significava ser destituído do fato de ser visto e ouvido por outros.

De acordo com o antigo pensamento, a esfera pública ou da polis se ocupava com as atividades pertinentes a um mundo comum à individual idade do homem, com a premissa de viver entre pares; a esfera privada da família se ocupava em atender às necessidades da vida, da sobrevivência e da continuidade da espécie > nessa última, considerava-se óbvio a respoinsabilidade do homem em cumprir a tarefa de suprimento do alimento e o da mulher na sobrevivência da espécie, pela natalidade. Em conformidade com esse pensamento, as eferas eram estritamente diferenciadas. Para A rendt (1989, p.39), "o que distinguia a esfera familiar era quenela os homens viviam juntos, por serem a isso compelidos por suas necessidades e carências". U ma vez que as necessidades da vida privada fossem atendidas, o homem voltava à sua participação na esfera da polis, que constiuía a esfera da liverdade. "Ser livre significava ser isento da desigualdade presente no ato de comandar, e mover-se numa esfera onde não existiam governo nem governados". A esfera política onde todos eram iguais, significava viver entre pares e lidar somente com eles (ARENDT, 1989, p.42).

Essa separação entre o público e o privado gerou uma dicotomia entre as questões relacionadas ao gênero, no qual foram atribuídos os papéis aos homens e as mulheres no casamento e na famíulia. Enquanto aos homens era reservado o mundo público, ensejando o trabalho remunerado para atender às necessidades materiais da família, cabia às mul heres e às crianças o mundo privado, cujo espaço era destinado ao trabalho doméstico e para atender as necessidades afetivas. Este é o modelo de família que se tornou o padrão dominante nas sociedades industrializadas. Desta forma, como afirma Vaitsman (1994, p.60) "a sociedade industrial moderna constiui-se entre outras coisas, pela separação do público e do privado e pela doutrina das esferas separadas e naturezas sexuais desiguais, expressas na ideologia, nas políticas e na legislação".

\section{A FAMÍLIA EM QUESTÃO}

À medida que o mundo se foi modernizando, as questões que dizem respeito à esfera da vida privada, da família, transformaram-se em interesse col etivo, muito embora as duas eferas, público e privado, "constantemente recaiam uma sobre a outra, como ondas do perene fluir do próprio processo da vida" (A RENDT, 1989, p.42). Na maioria das vezes, é difícil determinar quais atividades pertencem à esfera pública ou à esfera privada. A lgumas coisas como o trabal ho fora de casa, partidos políticos e clubes podem ser facilmente idenficadas como do âmbito da esfera pública, enquanto o casamento e o cuidado dos filhos são identificados como da esfera privada. Qualquer coisa, Dora das indicações sociais consolidadas, torna-se difícil situar a que esfera pertence. 0 público e 0 privado são termos comumente conhecidos eutilizados, porém fornecem uma visão simplista da organizaçãoi social, visto que existe a própria dificuldade de distinguir qual 0 alcance do público e do privado (SAPSFORD, 1995).

A tual mente, a familia é uma área crucial contígua das duas esferas. Simultaneamente é incorporada pela esfera privada e é objeto da esfera pública aberta à manipulação (SAPSFORD, 1995). 0 cuidado com a saúde e a educação dos indivíduos é questão que está intrinsecamente ligada a ambas as esferas. No momento em que é dada a responsabilidade à família para o cuidado de seus membros, 0 poder público determina, por suas políticas, as ações a serem desempenhadas, porém com o exercício descontextualizado da realidade. A questão da licença-maternidade, direito assegurado pela nova constituição, está hoje colocada em discussão, no sentido de diminuir o tempo de afastamento da mulher do trabal ho. Os países desenvolvidos, como a N oruega tem procurado ampliar o período, atualmente de 46 semans, facilitando a amamentação e o vínculo afetivo da criança com a família, assim favorecendo o crescimento e 0 desenvolvimento humano; em nosso país os governantes e os legisladores parecem ignorar esse direito, principalmente daquelas famílias desprovidas das mínimas condições para a sobrevivência. M uitas outras questões podem ser apontadas, como: as barreiras burocráticas nas instituições de atendimento à saúde que continuam impedindo o acesso dos pais às crianças hospitalizadas, a desarticulação do acompanhamento da assistência no pré e pós natal e o descompromisso com a manutenção de um serviço para o planejamento familiar. 0 tratamento dado a essas questões está centrado muito mais no individuo do que na família.

Embora as estruturas familiares setenham modificado ao longo do processo histórico, afamília éconsiderada o espaço mais adequado para o crescimento e desenvolvimento humano. É ela que primordial mente tem a incumbência de gestar e criar o indivíduo. Desta maneira é dado à família "o espaço indispensável para a garantia da sobrevivência, do desenvolvimento e da proteção integral dos filhos ou da forma como se vêm estruturando" (FERRARI e KALOUSTIAN, 1994, p.12). Porém o seu pleno desenvolvimento implica uma interação com as instituições públicas. 0 próprio Estatuto da Criança e do A dolescente, disposto na L ei n. 8069, dejulho de 1990, declara no Art. 4 que:

é dever da família, da comunidade, da sociedade em 
geral e do poder público assegurar, com absoluta prioridade a ef etivação dos direitos referentes à vida, à saúde, à alimentação, à educação, ao esporte, ao lazer, à profissionalização, à cultura, à dignidade, ao respeito, à liberdade e à convivência familiar e comunitária

Esta lei estabelece articulação entre o Estado e a sociedade e representa um avanço nas políticas públicas brasileiras, aproximando os limites dos espaçospúblicos e privados. Passados seis anos, a operacionalização é demasiadamente lenta, gerando um distanciamento de seus membros, se a ela não são oferecidas as oportunidades para o atendimento básico de subsistência?

Outra questão que cumpre apontar diz respeito ao ambiente em que a família está inserida. A casa ou a moradia, com suas divisões, constitui o cenário no qual é demarcado entre quatro paredes, o espaço da intimidadefamiliar. A s salas, os quartos e as demais dependências são os espaços de privacidade, onde os membros estabelecem as relações mais íntimas e procuram um refúgio na busca da liberdade. Contudo, este domínio da esfera privada está sujeito às obrigações com a sociedade, em que a privacidade de cada membro vai ao encontro da dimensão pública do outro. 0 acesso a esta vida privada garantindo pela moradia, não écomumente encontrado em nosso meio pela maioria da população. Observa-se que as famílias dos bairros populares vivem em domicílios precários, fazendo parte muito mais dos espaços da esfera pública do que da esfera privada. M ello (1995, p.58), ao abordar as questões sobre a família declara que "Iado a lado com a conquista diária do alimento, sempre escasso, conquista-se um espaço no interior das casas pequeníssimas, (...) onde não é só impossível a intimidade, como há uma col etivização forçada que constitui o núcleo obrigatório da vida em família".

A medida que o tempo foi passando, as questões que indicam uma relação com a esfera da vidaprivada, da organização da vida familiar, principalmente dos aspectos que envolvem as mulheres no desempenho de seus papéis, tem sofrido profundas transformações. A inclusão da mulher no mercado de trabal ho fora do lar e a sua luta pelos direitos de cidadania desafiaram os limites impostos tradicionalmente pela sociedade. Vaitsman (1994, p.191) declara que "ao derrubar as barreiras do mundo público, no enfrentamento das diferentes práticas da vida cotidiana, as mulheres modificaram os rumos da construção da identidade feminina e descontruíram os significados de um feminino que se colocava não só como diferença, mas como submissão ao masculino".

Embora as mudanças ocorridas nos últimos séculos tenham modificado al gumas regras estabelecidas, éainda uma presença marcante a característica que determinou a familia como pertencente à esfera privada, a qual responsabilizava a mulher pelo cuidado dos filhos. A s leis constituem as regras ditadas pela esfera pública, dominadas essencialmente pelo gênero masculino, que reflete a sua visão de mundo, definindo o papel da mulhercomo cuidadora.

Os estudos sobre afamília têm revelado que, na maioria das vezes, cabe à mulher a responsabilidade do cuidado dos filhos ea manutenção da estrutura familiar. Pais ausentes, que abandonam as suas famílias pela separação conjugal ou principlamente, em decorrência das causas sociais, tem contribuído para o aumento defamílias monoparentais, gerando formas distintas de articulação entre os membros da família e a sociedade. Em virtude disto "o mundo familiar mostra-se numa vibrante variedade de formas de organização, com crenças, val ores e práticas desenvolvidas na busca de soluções para as vicissitudes que a vida vai trazendo (SZIM ANSK I, 1995, p.27).

A enfermagem na sua práticaassistencial se depara com muitas dificuldades em transitar nesses espaços. Embora busque uma interação com as famílias, compreendendo a importância de suas crenças e valores no processo saúdedoença, enfrenta situações complexasgeradas pela incompatibilidade prática entre o que édefinido pelas políticas sociais edesaúde esua aplicabilidade. A negociação e o trabaljo interdisciplinar juntamente com a participação ef etiva da família são caminhos trilhados por todos aqueles que visam uma melhor qualidade de vida na sociedade. Longe de uma pretensão de esgotar este tema por aqui, mesmo porque ele não se esgota pela própria dinamicidade da sociedade, penso que a luta por uma igual dade universal ainda continua, equea dicotomia entre o público e privado, geradora das diferenças, está sujeita a transformações. A inda que haja muitas dificuldades de equacionar os aspectos relacionados a ambas as esferas, é preciso empregar todas as forças, no sentido de oferecer condições para termos uma vida mais digna e mais humana.

\section{REFERÊNCIAS}

1. ARENDT, Hannah. A condição humana. 4. ed. Rio de janeiro: Forense Universitária, 1989.

2. ARIES, PIhippe, DUBY, George. História da vida privada. São Paulo: Companhia das Letras, 1994. v.2.

3. CARTER, B etty, M CGOLDRICK, M ônica. As mudanças no ciclo de vida familiar: uma estrutura para a terapia familiar. Porto A legre: A rtes M édicas, 1995, p. 65-83.

4. ENGELS, Friedrich. A origem da família, da propriedade privada e do estado. 13. ed. Rio de J aneiro: B ertrand B rasil, 1995.

5. FERRARI, M ario, KALOUSTIAN, Silvio M. Introdução. In: KA L OUSTIA N, Silvio M anoug (Org). Família brasileira: a base de tudo. São Paulo: Cortez, 1994. p.11-5.

6. MELLO, Sylvia Leser. Família: perspectiva teórica e observação factual. In. CA RVA L HO, M aria do Carmo B randt (Org). A família contemporânea em debate. São Paulo : Cortez, 1995. p.51-6.

7. SAPSFORD, Roger. Endnote: public and private. In: MUNCIE, J on et al. Understanding the family. L ondon: Sage Publications, 1995. p.317-22.

8. SZYMANSKI, Heloisa do Carmo Brant de (Org.). A família contemporânea em debate. São Paulo : Cortez, 1995. p.23-7.

9. VAITSMAN, J eni. Flexíveis e plurais: identidade, casamento e família em circunstância pós-modernas. Rio de Janeiro: Rocco, 1994. 